\title{
Smart Authentication and Secured Engine Unlocking System for Automobiles
} Bhargava R*, Amulya H C, Jyothi K P, Keerthana R

${ }^{* 1}$ Assistant Professor, Department of Computer Science and Engineering Nagarjuna College of Engineering and technology Bengaluru, India

${ }^{234}$ B.E. Students, Department of Computer Science and Engineering Nagarjuna College of Engineering and technology Bengaluru, India

\begin{abstract}
Article Info

Volume 8, Issue 3

Page Number : 653-659

\section{Publication Issue}

May-June-2021

\section{Article History}

Accepted : 10 June 2021

Published : 15 June 2021

As human life started to evolve on this earth, the craving for smart automobiles has increased, and adding a vehicle security system to secure the automobile from theft in parking and in unsecured places is important. This paper proposes the design and development of smart system to prevent theft that uses biometric authentication to access the door and to start the engine of the automobile. This system initially uses the fingerprint module that takes the real time fingerprint of a person trying to open the vehicle door and compares it with the authorized person's fingerprint and then allows or denies the access to door, and secondly the camera takes the image of a person trying to start the engine and compares with the authorized person's image to allow or deny the access to the engine. In case of detection of unauthorized fingerprint, the GSM module sends the message to the owner and in case unauthorized person detected by camera it sends the captured image with alert message to owner. The system is developed using raspberry pi, GSM module, fingerprint module, pi camera, dc and servo motor.
\end{abstract}

Keywords : Biometrics, raspberry pi, fingerprint module, GSM module, Email, OpenCV, LBPH, Pillow, face Cascade

\section{INTRODUCTION}

In the modern epoch the requisite and significance of luxury and comfortable lifestyle is flourishing, the use of automobiles as become an essential part of the daily life, without automobiles human life would be topsyturvy. Many researchers have been working on the anti-theft systems of the automobiles since years and there are many systems being built as a solution to such issues. The biometric and non-biometric are the methodologies which were used in many old security systems and can be used in future for security purposes as it would be very effective. Sometimes these non-biometric methods based systems may fail due to encryption of decrypted data or password hacking, but it is almost impractical to make the replica of idiosyncratic characteristics. 
Biometric authentication methodology is very effective and latest and it uses the techniques like Fingerprints, facial recognition, iris recognition, retinal identification, voice recognition. The artificial intelligence is a fundamental and most effective field which involves many fields in it, here we are making use of the most popular and widely used biometric techniques and computer vision which is used to train the computers to elucidate and to understand this visual world. One of the most effective technique we are using here is a facial detection and recognition that is part of computer vision, it includes various python libraries and packages like openCV that detects faces from real time videos and images, pillow is a imaging library in python which supports in various functions with respect to images, $\mathrm{LBPH}$ algorithm is a simple approach which during the feature extraction process extracts the landmarks on face to convert into LBPH histogram, and cascade classifier to detect the objects in the captured images. For coding the raspberry pi we need to convert our images into a numpy array and then train our model.

So, firstly we need to use the python image library, to grab an image, and then convert it into gray scale to resize the images. Then we will be converting the images into a numpy array, which means images will be converted to numbers, then create a dictionary where in particular name or an id is given to every label and a rectangular box is attached to every recognized face, then facial detection can be done using the face cascade. Finally, we will use the LBPH face recognizer algorithm and the trained model as an yml file. Facial recognition and detection systems are more advanced, not very difficult to deploy and people can be identified without their knowledge. The one more technique used in this project is a fingerprint recognition which can be put under a most popular biometric to date as it is capable of using distinct number of approaches for classification purpose.

\section{LITERATURE SURVEY}

In [1] the author is introducing the anti-theft security system to start the engine using biometrics, here they used a camera to capture the person image who is trying to start an engine. Only for authorized user the engine starts else a captured image will be sent to the owner as an alert, as the main step to access any car is to open the door, the security system should be implemented at the door itself.

In [2] authors are proposing the comprehensive unified frame work for vehicle security systems. The vehicle location will be located and tracked by using GPS and GSM, face detection and recognition techniques are runs on the by using microprocessor it is settled on board with the vehicle. This anti-theft control system could also be integrated the national Digitized ID card. By the use of microprocessor control system, it's over heating physically. And the main issue is it should not contact with the other external devices.

In [3] authors are proposing a vehicle security system for an image processing, which was based on authentication for a real time user. Here they used face detection and recognition techniques and microprocessor it is settled on board with the vehicle. And microcontroller is used to receives the location from GPS through GSM module. The vibration sensors are used to find the accidents, in this case here In [4] the author is introducing the advance technology in the area of increasing the security of vehicle theft. Iot and RFID based robbery detection is implemented by making use of a cloud. A RFID tags are adopted for the purpose of authentication, whenever stealing take place the authorized one gets the mail. As cloud is being used, it may lead to the crashing of data and security issues.

In [5] the authors are proposing the Iot based door access control system. By making use of a face recognition, pi camera, and here they used Haar face recognition algorithm to capture image using OpenCV, here they used telegram application to 
represent the allow and deny access of a door. Haar face recognition has many challenges is the extent of its performance in the detection of gadgets because of the non-invariant nature of the regular Haar-like functions.

In [6] the authors are introducing a Iot based vehicle theft detection to detect the robbed vehicle. When the dc motor starts it indicates the vehicle theft occurs, Arduino is used to activates GPS and GSM. Longitude and latitude reading of a vehicle are posted using Iot with the help of $\mathrm{Wi}-\mathrm{Fi}$ module so many issues may cause by using $\mathrm{Wi}-\mathrm{Fi}$ module like a range offered by Wi-Fi network is limited.

In [7] authors are proposing the facial recognition security system, here it provides an alarm for house caller and it gives an information about callers in a web pages and mobile applications. here intelligent security system is used for face identification, integrated camera captures a picture of a facial part only, instead of integrated camera they would have to use the pi camera, by the use of integrated camera may cause some serious privacy issues, hacker can enable it when you are not aware and then use it to film illegal process.

In [8] authors are introducing a smart anti-theft system by making use of a face recognition, to track the exact location of vehicle they used a GPS and GSM. Sometimes GPS location can be inaccurate. In GSM there is no end-to-end encryption for user data.

In [9] the author is introducing a security which is needed especially for the vehicle thefting by using Radio frequency. By using Arduino and RFID tag sensor, there will be an ID card which sends signal. Due to external electromagnetic intervention can cause the limit of the RFID remote reading.

In [10] the author is introducing the upcoming technology which is machine to machine commination by using sensor for interaction, Iot gives a greater domain and Arduino Uno R3, sensor and small phone is being used. The access of the car is given through GPS to the authorized person. As M2M gives through GPS to the authorized person. As M2M needs constant internet connection, the sensing may get slower.

In [11] the author is introducing a mechanism for protecting the vehicle from stealing. The security is given by the association of Bluetooth, camera and sensors to avoid accident. The safety is given by using fingerprint by using MATLAB. Bluetooth aid to detect the place of the car around the distance of $10 \mathrm{~m}$ only. It has low bandwidth as compared to the Wi-Fi. In [12] the author is introducing great idea of monitoring speed of vehicle by using RFID.RFID reader contains speed checking camera and snap camera. Each RFID reader with camera contain the vehicle information. The RFID reads the vehicle speed. Sometimes tag may get collision which leads the reader to receive many tags signals at same time.

In [13] the author is introducing the advance vehicle security system by GSM and GPS system to protect robbery of vehicle as well as to get vehicle. GPS tracks exact position of the vehicle; GSM is used to send the information to GPS. But sometimes GPS signals are accurate the location cannot be predicted.

In [14] the author is introducing a vehicle position approach based on RFID to provide accurate vehicle position stored in the tag. The place is tracked by the latest tag position by hr use of kinematics algorithm. A few instances RFID fails to revel in the automobile due to velocity and motion of tags, antenna layout, cable kind and period.

In [15] authors are proposing a lock system by real time facial recognition. Face recognition method is found by the information of colour of skin. The Face detection by using an algorithm, face detection is on the component analysis by use of adaboost algorithm it is difficult to detect a feature because of complex background and the center part of a face has even intensity values.

In [16] the author is introducing recognition mechanism form license vehicle plate which provides security of vehicle. When some unknown vehicles enter the building. By RFID tag and camera, the plate of the vehicles is checked to identify the unidentified 
plate number. Sometimes in case of bad weather and hindrance may lead automatic LPR system not effective.

\section{PROPOSED SYSTEM}

\section{A. BLOCK DIAGRAM}

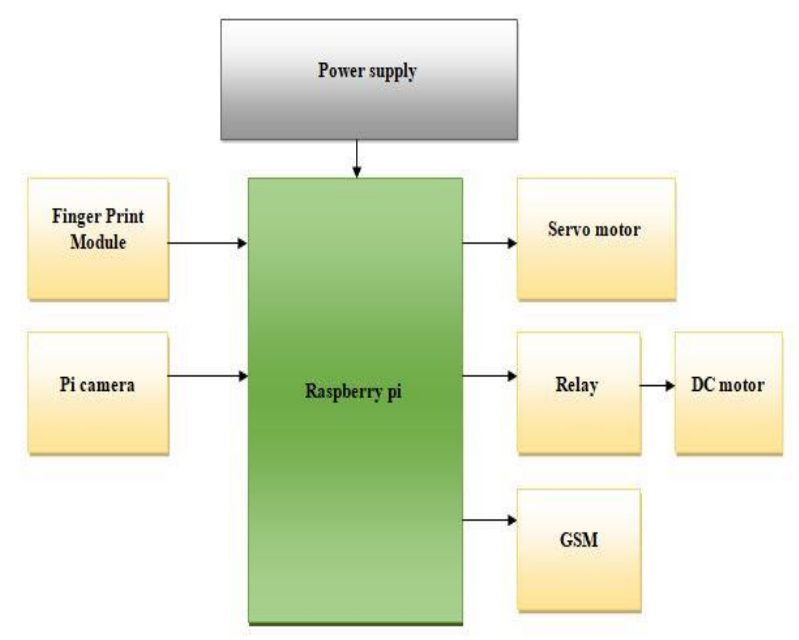

Fig. 1 Block Diagram of vehicle unlocking system

In the above block diagram, the pi camera and fingerprint module acts as the inputs, the output devices include the servo motor, a DC motor, relay and a GSM module.

The proposed system uses fingerprint module R305 used to scan the fingerprint is interfaced with main unit with TTL serial converter, Raspberry pi $3 \mathrm{~b}+$ model which is the brain of our proposed system takes all the inputs and actuates the output devices by taking required action and it includes 64-bit quad core processor, wireless LAN, fastest Ethernet, built in Bluetooth, CSI, SD Interface, HDMI. Because of its built-in properties, low cost and high reliability this is the most suitable board we found. SIMCom SIM900A GSM module transmits the SMS on GSM cellular network. Pi camera acts as a transducer that is used to capture images and it is attached to main unit via a ribbon cable to the CSI port on the Raspberry Pi. Actuators, we have used servo motor SG-90 as an indication of door access, relay will be activated or deactivated by energizing or de-energizing the coil which will control the load (dc motor) that used as an indication of engine access.

\section{FLOWCHART}

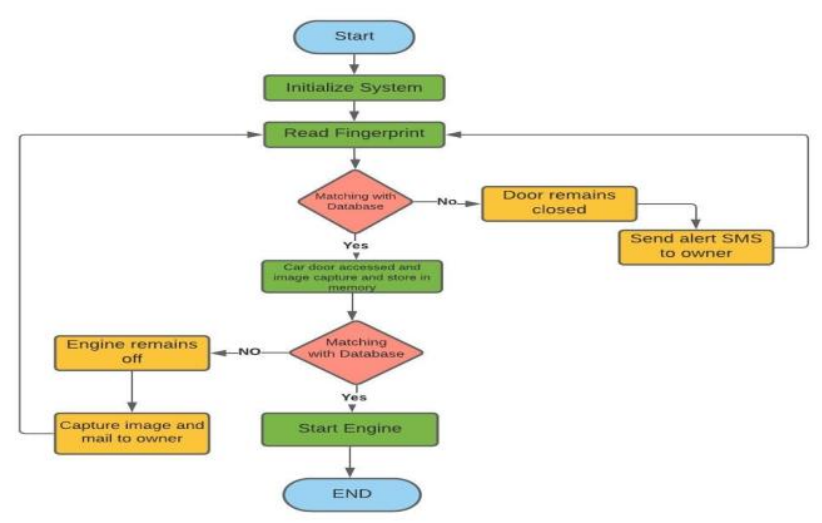

Fig. 2 Flow chart of our proposed system.

The above flow chart is explained in detail as follows.

If we consider any automobile in order to start engine first we need to open the car door, so introducing the stronger security measures from first step itself is most important, which is achieved in the design of our system. When a driver wants to open the car door he needs to scan his finger print which will be done through the fingerprint module R305 placed near the car door. Fingerprint module sends the data in the form of signal to raspberry pi, This raspberry pi then takes required action by comparing the fingerprint scanned by fingerprint module with the fingerprint samples that were already being trained and stored in raspberry pi database, Only if the driver is authenticated person, the car door opens that will be indicated by raspberry pi sending signal to servo motor SG 90 as high, else the alert message will be sent to the owner using SIMCom SIM900A GSM module.

Only if the car door is opened the camera will be turned on to capture the image of the person sitting on the car seat, here we have used pi camera. Once the image is captured, it compares that image with the authorized images stored in raspberry pi and only if 
there is a match, the engine starts that will be indicated by raspberry pi sending signal as high to dc motor which is interfaced through relay, else the captured image along with the alert message will be sent to the owners' email, and the car engine remains off.

\section{RESULTS}

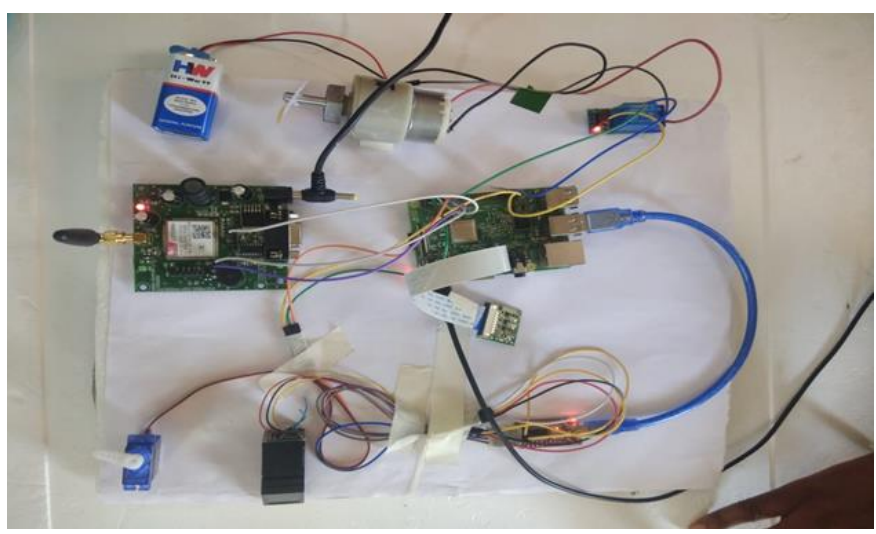

Fig. 3 The final setup of the proposed system as per the block diagram.

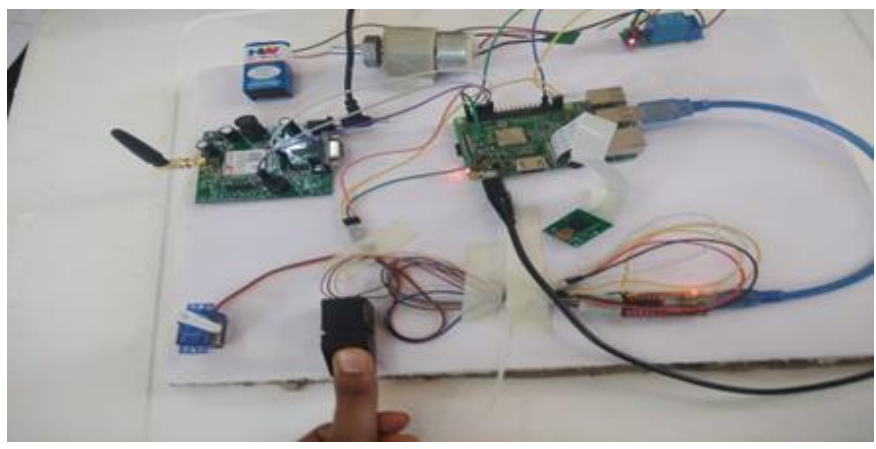

Fig. 4 Successful door access indicated by servo motor rotation when an authorized person tries to access the vehicle using the fingerprint module.

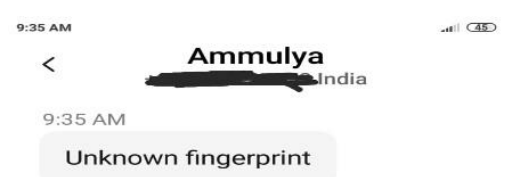

$+\quad$ Text message
Fig. 5 Message being sent from the SIM inserted in the GSM Module to an authorized person when unknown fingerprint is detected by the fingerprint module.

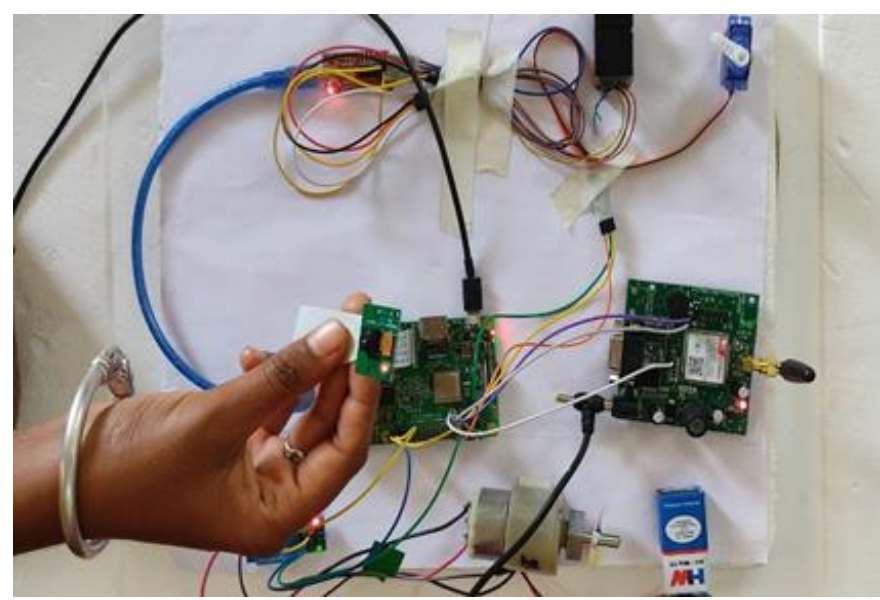

Fig. 6 After the capture of image by pi camera and then by Successful detection and recognition of authorized person, the engine is started which is indicated by green light in relay and dc motor rotation.

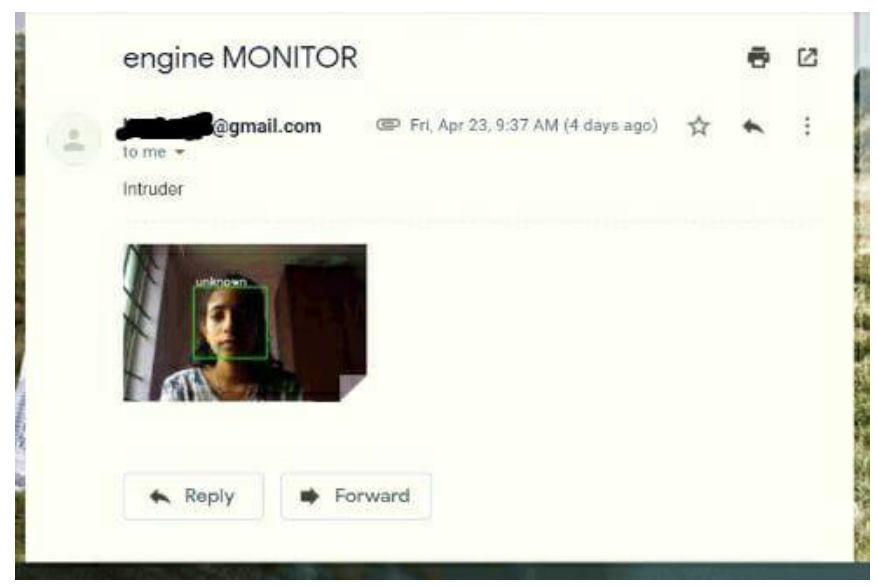

Fig. 7 Successfully detected unknown person as soon as pi camera captures the image and email being received to authorized person's mail id.

\section{CONCLUSION AND FUTURE ENHANCEMENT}

This paper has introduced a antitheft system for automobiles which ensures that automobile users can park their vehicles anywhere without worrying about vehicle theft and misuse, as this proposed system is simple, user hostile and reliable that alerts the owner with the message if someone tries to open the car 
door so that he can arrive there immediately and as this system also captures image of the person trying to start the engine without their knowledge, it will help the owner to see the intruder's image on his email and forward it to cops immediately.

In future we aim to integrate the GPS system to track the location and we also use cloud computing to store all the log-in information in computing storage.

\section{REFERENCES}

[1]. Mahesh R. Pawar, Imdad Rizvi "IoT Based Embedded System for Vehicle Security and Driver Surveillance" the 2nd International Conference on Inventive Communication and Computational Technologies (ICICCT 2018) IEEE Explore Compliant.

[2]. Hussam Elbehiery, Khaled Elbehiery "Comprehensive Unified Framework for Vehicle's Security Systems" International journal of creative research thoughts (IJCRT), 2020 IJCRT Volume 8, Issue 8 August 2020, ISSN: 2320-2882.

[3]. K.K. Dube, P.S. Satalkar, D.V. Warule, S.T. Patil, "Face recognition system for unlocking automobile using gsm and embedded technology" International Research Journal of Engineering and Technology (IRJET) e-ISSN: 2395-0056 Volume: 06 Issue: 02 Feb 2019, ISSN: 2395-0072.

[4]. P. Devika, V. Prashanthi, Vijay Kanth, J Tirupati "RFID Based Theft Detection and Vehicle Monitoring System using Cloud" International Journal of Innovative Technology and Exploring Engineering (IJITEE) ISSN: 2278-3075, Volume-8 Issue-4, February 2019.

[5]. Amritha Nag, Nikhilendrao J N, Mrutyunjay Kalmath, "IOT Based Door Access Control Using Face Recognition",2018 3rd International Conference for Convergence in Technology (I2CT), pp 1-3
[6]. M Poushya, k. Rupasari, N. Supritha, K. Hema and R. Tejaswini, "IOT Based Vehicle Theft Detection",2018 IRE Journals, Electronics and Communication Engineering (ECE), Vasireddy Venkatadari Institute of Technology, pp 52-55.

[7]. Prof.K.T. Jadhao and Prashanth Balraj Balla "IOT Based Facial Recognition Security system",2018 Alamuri Ratnamala Institute of Engineering and Technology (ARIET) pp 1-4.

[8]. Yolanda D. Austria, Luisito L. Lacatan, John Gregory D. Funtera, Shawn C. Garcia, Jonet H. Montenegro, Laymar T. Santelices, "Face Recognition for Motorcycle Engine Ignition with Messaging System”,2017international Journal of Computing Sciences Research.

[9]. Yudhi Gunardi, Nofian Sudi K and Fina Supegina "DESIGN OF VEHICLE SECURITY SYSTEM USING RADIO FREQUENCY IDENTIFICATION" Vol-3 Issue-4 2017 IJARIIE-ISSN(O)-2395-4396

[10]. V. K. Sehgal, S. Mehrotra, and H. Marwah, "Car Security using Internet of Things," Power Electron. Intell. Control Energy Syst. (ICPEICES), IEEE Int. Conf., pp. 1-5, 2016.

[11]. Prabal Deep Das, Sharmila Sengupta, "Proposing the systems to provide protection of vehicles against theft and accident”,2016 IEEE Conference On Recent Trends in Electronics Information Communication Technology", pp 1681-1685.

[12]. Farrukh Hafeez1, Mohammad Al Shammrani2, Omar Al Shammary3 "Smart Vehicles Speed Monitoring System Using RFID” International Journal of Advanced Research in Electrical, Electronics and Instrumentation Engineering (An ISO 3297: 2007 Certified Organization) Vol. 4, Issue 4, April 2015.

[13]. PritpalSingh,Tanjot,Sethi,BunilKumar,Balabant aray, Bibhuti Bhushan Biswal "Advanced vehicle security system" 2015.International Conference on Innovations in Information, 
Embedded and Communication Systems (ICIIECS).

[14]. Jianqiang Wang, Daiheng $\mathrm{Ni}$ and Keqiang Li RFID-Based Vehicle Positioning and Its Applications in Connected Vehicles Sensors 2014, 14, 4225-4238; doi:10.3390/s140304225 ISSN 1424-8220.

[15]. S. Padmapriya \& Esther Annlin KalaJames, "Real Time Smart Security System Using Face Detection and Recognition",2012 International Conference on Computer Communication and Informatics (ICCI-2012), pp 1-6.

[16]. Dileep Kumar, Pankaj Pratap Singh and Shirshu varma "RFID and Camera-based Hybrid Approach to Track Vehicle within Campus" 2009 International Symposium on Computing, Communication, and Control (ISCCC 2009) Proc. of CSIT vol.1 (2011) (C) (2011) IACSIT Press, Singapore.

\section{Cite this article as :}

Bhargava R, Amulya H C, Jyothi K P, Keerthana R, " Smart Authentication and Secured Engine Unlocking System for Automobiles", International Journal of Scientific Research in Science and Technology(IJSRST), Print ISSN : 2395-6011, Online ISSN : 2395-602X, Volume 8, Issue 3, pp.653-659, May-June-2021. Available at doi : https://doi.org/10.32628/IJSRST2183147 Journal URL : https://ijsrst.com/IJSRST2183147 